\title{
Impacts of invasive plants on carbon pools depend on both species' traits and local climate
}

\author{
Philip A. Martin, ${ }^{1,2,3}$ Adrian C. Newton, ${ }^{2}$ and James M. Bullock ${ }^{1}$ \\ ${ }^{1}$ Centre for Ecology and Hydrology, Benson Lane, Wallingford, Oxfordshire, OX10 8BB UK \\ ${ }^{2}$ Centre for Conservation Ecology and Environmental Science, School of Applied Sciences, \\ Bournemouth University, Poole, BH12 5BB UK
}

\begin{abstract}
Invasive plants can alter ecosystem properties, leading to changes in the ecosystem services on which humans depend. However, generalizing about these effects is difficult because invasive plants represent a wide range of life forms, and invaded ecosystems differ in their plant communities and abiotic conditions. We hypothesize that differences in traits between the invader and native species can be used to predict impacts and so aid generalization. We further hypothesize that environmental conditions at invaded sites modify the effect of trait differences and so combine with traits to predict invasion impacts. To test these hypotheses, we used systematic review to compile data on changes in aboveground and soil carbon pools following non-native plant invasion from studies across the World. Maximum potential height $\left(H_{\max }\right)$ of each species was drawn from trait databases and other sources. We used metaregression to assess which of invasive species' $H_{\max }$, differences in this height trait between native and invasive plants, and climatic water deficit, a measure of water stress, were good predictors of changes in carbon pools following invasion. We found that aboveground biomass in invaded ecosystems relative to uninvaded ones increased as the value of $H_{\max }$ of invasive relative to native species increased, but that this effect was reduced in more water stressed ecosystems. Changes in soil carbon pools were also positively correlated with the relative $H_{\max }$ of invasive species, but were not altered by water stress. This study is one of the first to show quantitatively that the impact of invasive species on an ecosystem may depend on differences in invasive and native species' traits, rather than solely the traits of invasive species. Our study is also the first to show that the influence of trait differences can be altered by climate. Further developing our understanding of the impacts of invasive species using this framework could help researchers to identify not only potentially dangerous invasive species, but also the ecosystems where impacts are likely to be greatest.
\end{abstract}

Key words: carbon storage; ecosystem functioning; impact; invasive species; meta-analysis.

\section{INTRODUCTION}

Invasive plant species can damage the environment, human health or the economy via reductions in native biodiversity (Vilà et al. 2011), or alteration of ecosystem services (Pejchar and Mooney 2009). A major goal of invasion biology is to form general rules about how invasive plant species impact the ecosystems they invade (Parker et al. 1999, Ricciardi et al. 2013), to allow prediction and risk assessment. However, forming these general rules is difficult because of large differences in species' impacts on ecosystems (Liao et al. 2008, Vilà et al. 2011). This was illustrated by the meta-analysis of Vilà et al. (2011) in which less than half of ecosystem changes in response to plant invasion showed a statistically significant response, potentially giving the misleading impression that species invasions cause little impact on ecosystem properties, despite ample evidence

Manuscript received 17 August 2016; revised 25 November 2016; accepted 13 December 2016. Corresponding Editor: Brenda J. Grewell.

${ }^{3}$ E-mail: phil.martin.research@gmail.com to the contrary (Hulme et al. 2015). Generalizing about the impacts of plant invasions is challenging because invasive species represent a wide variety of life forms (Pyšek et al. 2008), and because invaded ecosystems differ in their plant communities and abiotic conditions. However, using functional effect traits of invasive species offers a potential method to generalize about changes resulting from invasion (Suding et al. 2008).

One of the most commonly reported changes in ecosystems following invasion by non-native plants is an increase in ecosystem carbon pools (Liao et al. 2008, Vilà et al. 2011). However, syntheses have failed to identify mechanisms that might explain the heterogeneity in invasive plant species effects on carbon pools. Previous syntheses of invasive species impact have focused on the traits of invasive species as predictors (e.g., Pyšek et al. 2012), often using trait values from the invasive's native range. However, theory suggests that it is the difference in trait values between invasive species and the native species in the community being invaded that determines ecosystem-level changes after invasion (Ricciardi et al. 2013). Castro-Diez et al. (2014) successfully tested this 
theory and showed that differences in native and invasive plant traits influenced post-invasion changes in nitrogen pools. Similarly, differences in the potential maximum height between native and invasive species may serve as a predictor of changes in carbon pools following invasion, as height relates to volume and thus biomass. Given that increases in aboveground biomass tend to enhance soil carbon as a result of increased input from litter and root material (Eldridge et al. 2011), differences in the height trait may also serve as a predictor of changes in soil carbon. Using traits measured in the native ranges of both invasive and native species in analyses may allow invasion biology to move beyond identifying the most damaging species to generalizing a priori about the effects of species in particular contexts.

Though using species' traits may aid generalization about the impacts of invasive species, the expression of plant traits can be highly plastic among environments (Funk 2008, Davidson et al. 2011). Thus, while maximum potential height (or any other trait) values might explain invasive species' impacts to some extent, the effect the local environment on the ability to achieve this potential height will limit the explanatory power of traits and trait differences. One means of accounting for this plasticity is to include climatic data in analyses, since within-species' variability in expression of traits such as maximum height can result from climatic differences between sites (Jakobs et al. 2004). Globally, plants tend to be taller nearer the equator (Moles et al. 2009) as a result of greater water availability in the wet tropics allowing plants to reach greater heights (Moles et al. 2009, Stegen et al. 2011). The water availability of novel ecosystems may alter the height that invasive species attain, thus making changes in carbon pools partly dependent on climate. We elaborate on this hypothesis in Fig. 1. The impacts of abiotic variation on functional trait expression, and the subsequent alteration of ecosystem functions is considered a key topic for community ecology (McGill et al. 2006, Violle et al. 2007) and invasion biology (Hulme and Barrett 2013).

In this study, we suggest that trait differences and climate interact to determine the impact of invasive plant species. Specifically, we use a global dataset of changes in carbon pools following non-native plant invasion to test the hypothesis that the impact of invasive species on carbon pools depends on (1) the difference in maximum attainable heights for the invasive and native (i.e., the single native species that is dominant in the uninvaded community) plant species as measured in their native ranges and (2) water availability in the novel ecosystem. In addition, we test the hypothesis that the difference in attainable height for invasive and native species is a better predictor of changes in carbon pools than the maximum height of the invasive species. Because there is a direct link between plant height, biomass and carbon storage, this focus gives us a robust relationship with which to investigate the more novel question about the role of climate in modifying how trait differences predict impact. Importantly, this approach uses trait values for invasive species from their native ranges, with the aim of enabling prediction of the impact of invasive species prior to their arrival.

\section{Methods \\ Systematic review}

To collate data on the carbon impacts of invasive plant species we first conducted a systematic review following Pullin and Stewart (2006). Our criteria for inclusion were:

1. The species studied were invasive, rather than solely non-native. As such species had to be described as non-native and invasive in the study, and/or the species was classified as invasive by the Global Invasive Species database (http://www.iucngisd.org/gisd/) or the CABI Invasive Species Compendium (http://www.cabi. org/isc/).

2. Quantitative, replicated measurements were supplied of the effects of invasive plant species on aboveground biomass or soil carbon at one or more invaded site and a relevant un-invaded control. We did not limit the maximum depth of soil carbon measurements to a specific range, but $70 \%$ of studies sampled to a depth of $<20 \mathrm{~cm}$. Studies which used sites where invasive species had been removed as a control were excluded due to the possibility of legacy effects (Corbin and D'Antonio 2012).

3. Details of the study location were given in the form of Latitude and Longitude, or a description of the location that was detailed enough for coordinates to be assigned.

4. Invasive species showed signs of displacing native species, rather than just increasing local species pools. Use of studies in which invasive species do not compete with native species would potentially add noise to the analysis by reducing correlation between trait differences and changes in ecosystem properties.

5. Studies were carried out in terrestrial ecosystems, excluding wetlands. As we were interested in investigating the influence of differences in plant height and water stress on invasion impacts any measurements of impact in aquatic or wetland ecosystems may have masked the impact of water stress.

6. Studies gave the scientific name of both the invasive and dominant native species in the uninvaded site.

A key assumption of this analysis is that invasive species displace or reduce the abundance of the dominant native species and that the invasive species subsequently becomes dominant. Thus, it is valid to compare the traits of the invasive with the single species which is most dominant in the uninvaded system.

Any invaded sites that differed in management or anthropogenic disturbance from uninvaded sites were excluded since these differences could confound the effects of invasive species. Any sites that were subject to deliberate establishment of invasive species, such as plantations, were 


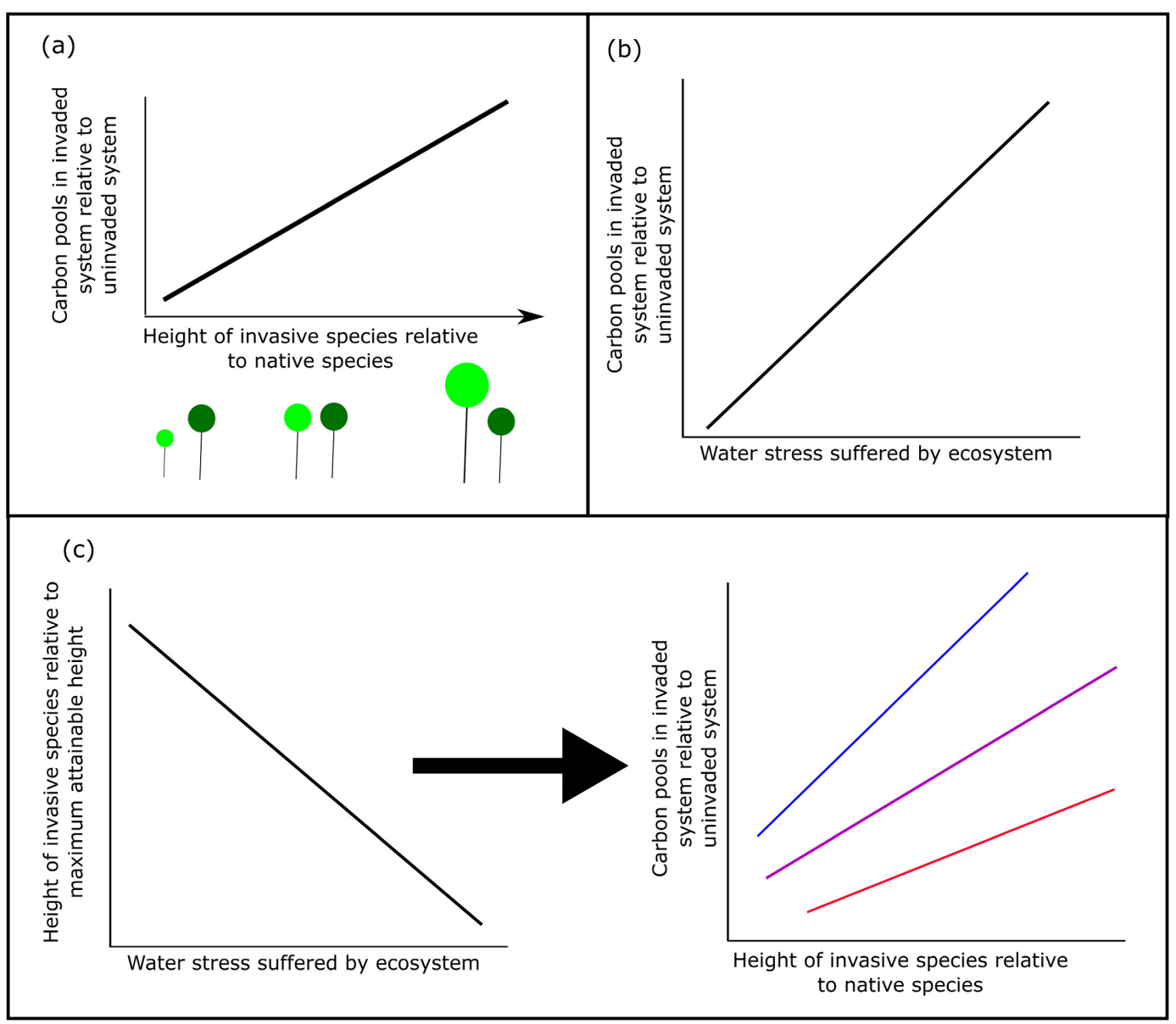

FIG. 1. Qualitative predictions of hypothesized relationships between changes in ecosystem carbon pools and (a) maximum height of invasive species relative to dominant species, (b) ecosystem water stress and (c) interactions between water stress and maximum height of invasive species relative to dominant species. In (a) as maximum height of invasive species relative to dominant species increases, so do carbon pools in invaded relative to uninvaded systems. The diagram below the figure represents the relative difference in invasive (light green) and native (dark green) maximum heights. Any deviation of the intercept in (a) away from zero may suggest traits other than height play an important role in determining carbon pools. In (b) post-invasive carbon pool changes are positively related to ecosystem water stress as observed by as a result of increased decomposition rates in wetter climates (Smith et al. 2013). In (c) increasing water stress reduces the height invasive plants can achieve, thereby resulting in lower gains in carbon pools for water stressed systems (red line) when compared with intermediate or non-water stressed systems (purple and blue line respectively). [Color figure can be viewed at wileyonlinelibrary.com]

not considered since this represents a change in land use and management as well as in species composition.

\section{Data collation}

To collate data we searched ISI Web of Knowledge (last search carried out 10/02/16) using the search terms: (invas* OR non-native OR alien OR exotic) AND (plant OR grass OR shrub OR tree OR weed OR forb OR vegetation) AND (biomass OR product* OR carbon). Following this we selected papers that fell within the topics 'Environmental Sciences/Ecology' and 'Conservation biology.' Articles were excluded, first if titles were deemed irrelevant, and then by examining abstracts. The remaining articles were read in full and retained only if they met our inclusion criteria. Where there was evidence that relevant data had been collected but were not presented in the publications they were requested from the authors. The reference lists of papers meeting the inclusion criteria, as well as those of relevant reviews (Liao et al. 2008, Vilà et al. 2011), were also checked for additional relevant studies. For each study deemed relevant the mean; standard error, standard deviation, or confidence interval; and sample size were extracted for invaded and uninvaded ecosystems. Where data were presented in graphs they were extracted using the program datathief (Tummers 2006).

Data on the maximum attainable height $\left(H_{\max }\right)$ in meters of invasive and native species was collated using the LEDA (Kleyer et al. 2008) and ECOFLORA (Fitter and Peat 1994) trait databases along with internet searches when this information could not be found elsewhere. It is 
well known that traits of species, such as height, can change when a species colonizes areas outside of its native range (Davidson et al. 2011). However, our work aims to predict how well traits of a species in its native range predict ecosystem impact in non-native areas and so we used trait values taken in species' native ranges. Where more than one trait value was available we calculated the geometric mean value to reduce the impact of extreme values, following Wilman et al. (2014). Data on $H_{\max }$ were available from websites for many more species than from trait databases, so to check the accuracy of these data we assessed the correlation between $H_{\text {max }}$ values from internet sources and values from the trait databases for species where data were available from both sources. The two were very highly correlated $\left(n=56, R^{2}=0.94\right)$, though web based sources had $H_{\max }$ values that were $11 \%$ lower than those in the LEDA and ECOFLORA trait databases on average.

Water stress of ecosystems was assessed using climatic water deficit (CWD). CWD was computed by summing the difference between monthly precipitation and evapotranspiration only when the difference is negative (water deficit). Higher values indicate more extreme water stress. The metric has been used to assess the effects of regional droughts (Van Mantgem and Stephenson 2007, Martin et al. 2015a) and global-scale climatic differences in water availability on forest structure (Stegen et al. 2011). We obtained these data from a global gridded dataset with a 2.5 arc second resolution produced by Chave et al. (2014), which are available at http://chave. ups-tlse.fr/pantropical_allometry.htm. We subsequently extracted mean CWD values within $2.5 \mathrm{~km}$ buffers of all sites we collated data for.

\section{Analysis}

To test the predictive ability of trait values of the invasive species alone we used the $H_{\max }$ for the invasive in each study (hereafter termed $H_{\text {Inv }}$ ). We used the $\log$ ratio of differences in species' heights (hereafter termed $\left.H_{\text {diff }}\right)$ as the measure of the differences in $H_{\max }$ of the invasive species and its counterpart native species. Negative values of $H_{\text {diff }}$ indicate that invasive species had a lower $H_{\max }$ that the native species and positive values that they had a higher $H_{\max }$. We investigated whether the effect of $H_{\text {diff }}$ was influenced by ecosystem water stress, measured as CWD. Prior to analysis CWD was standardized using the methods of Schielzeth (2010). To do this the mean of CWD was subtracted from each unique value, which was then divided by the standard deviation of CWD. This approach improves model performance and the interpretability of coefficients (Schielzeth 2010).

The difference in carbon pools between the uninvaded and invaded systems was assessed using the response ratio effect size (Hedges et al. 1999), with each study weighted by the inverse of the within study variance to give more precise studies more weight (Borenstein et al. 2009). For both aboveground biomass and soil carbon we assessed eight different possible models: a null, intercept only model; including only $H_{\text {Inv }}$; including only $H_{\text {diff }}$; including only CWD; an additive model of CWD and $H_{\text {diff }}$, an additive model of CWD and $H_{\text {Inv }}$; including an interaction between CWD and $H_{\text {diff; }}$, and including an interaction between CWD and $H_{\text {Inv }}$. Some studies we selected used a single uninvaded site for comparison with multiple invaded sites. To control for this pseudoreplication, we bootstrapped the analyses by randomly selecting a single comparison when studies used the same uninvaded reference. This process was repeated 10,000 times and statistics of parsimony calculated from median values, following the approach of previous studies (Sodhi et al. 2009, Curran et al. 2014, Martin et al. 2015b). Model selection was performed by comparing model $\mathrm{AIC}_{\mathrm{c}}$, with the model with lowest median $\mathrm{AIC}_{\mathrm{c}}$ selected as the best. The best model was then bootstrapped 10,000 times and goodness of fit statistics and coefficients calculated from median values. To assess the goodness of fit of metaregression models the $R^{2}$ analogue was calculated as:

$$
R^{2} \text { analogue }=1-\left(\frac{T_{\text {residual }}^{2}}{T_{\text {total }}^{2}}\right)
$$

where $T_{\text {total }}^{2}$ is the total between study variance and $T_{\text {residual }}^{2}$ is the residual variance of the model after independent variables have been accounted for. All analyses were carried out in R 3.23 ( $\mathrm{R}$ Development Core Team 2011) using the metafor package (Viechtbauer 2010).

In addition to analyses of the effects of invasive plants on carbon pools we assessed how representative the data we used were of the phenomena we were attempting to characterize. We did this because we agree with Gonzalez et al. (2016) that where possible meta-analyses should examine biases that may affect their ability to form generalizations. In the case of our study, ideally this meant comparing the frequency distribution of invasive species $H_{\max }$ heights from the studies we used to that for all invasive plant records and doing the same with CWD values. However, $H_{\max }$ data were not available for all known invasive species and so we used data on growth form instead. To test for biases we used the R package rvest (Wickham 2015) to "scrape" data from the CABI invasive species compendium (http://www.cabi. org/isc/) on the taxonomy and locations of recorded invasive plant species. We then grouped invasive plants into broad functional groups, and compared the percentage represented by all invasive plant species recorded to those used in our study. To assess climatic biases we extracted data on CWD for all locations where invasive plant species have been recorded and compared histograms of this to the data on CWD for sites we used in our study. Although the data on invasive species records are likely to be biased themselves (Pyšek et al. 2008), these are the only data available that allow assessment of bias.

\section{RESUlTS}

The search terms of our systematic review identified 5,552 articles. After excluding papers deemed irrelevant 
the full text of 267 articles was assessed. Of these papers we identified 43 that fully met our criteria, 16 with data on aboveground biomass and 35 with data on soil carbon (see Appendix S1 for more information). From these papers we extracted 27 and 62 pairwise site comparisons for aboveground biomass and soil carbon respectively. These papers detailed 47 different invasive species and 70 different dominant native species. $92 \%$ of studies were carried out in the Northern hemisphere, largely in North America and Europe (Appendix S1: Fig. S1).

The most parsimonious model for describing postinvasion changes in aboveground biomass included an interaction term between CWD and $H_{\text {diff }}$ (Table 1 , Fig. 1). This model provided a relatively good fit to the data $\left(R^{2}=0.30\right) . H_{\text {diff }}$ was positively correlated with changes in aboveground biomass (slope $=0.88, \mathrm{SE}=0.1$, $P<0.001)$. Though the model with lowest $\mathrm{AIC}_{\mathrm{c}}$ suggested a negative relationship between CWD and changes in post invasion aboveground biomass, this effect was not statistically significant (slope $=-0.16, \mathrm{SE}=0.3, P=0.59$ ). However, the effect of $H_{\text {diff }}$ was reduced in water stressed climates, resulting in reduced biomass in drier climates (interaction term $=0.16, \mathrm{SE}=0.07, P=0.016$ ). Taken together these results indicate that as difference in $H_{\max }$ increases, and water stress is reduced (i.e., a decrease in CWD), post-invasion biomass increases (Fig. 2). Model predictions also suggest that even when $H_{\text {diff }}=0$ (i.e., invasive and native species have similar $H_{\max }$ ), there tends to be an increase in aboveground biomass in invaded systems (Fig. 1). All models containing $H_{\text {Inv }}$ had little explanatory power and were less parsimonious than the null model (Appendix S1: Table S1).

In contrast the most parsimonious model for describing post-invasion changes in soil carbon included only $H_{\text {diff }}$ (Fig. 3). This model provided low explanatory power $\left(R^{2}=0.09\right)$ and was marginally more parsimonious than the next best performing model that included only $H_{\text {Inv }}$ $\left(\Delta \mathrm{AIC}_{\mathrm{c}}=0.89\right) . H_{\text {diff }}$ was positively correlated with changes in soil carbon, but this slope was non-significant at the $5 \%$ level (slope $=0.09, \mathrm{SE}=0.05, P=0.059$ ). The intercept of the model was positive (intercept $=0.16$, $\mathrm{SE}=0.07, P=0.032$ ) suggesting that even when invasive and native species have similar maximum heights, there tends to be an increase in soil carbon following invasion (Fig. 3).

Relative to records of invasive plant species occurrence, our data were biased towards less water stressed ecosystems (Fig. 4a). Our study also overrepresented graminoid invasive species, and underrepresented herb and shrub invasive species (Fig. 4b). However, our study had at least one record for an invasive species of each growth form.

\section{DisCUSSION}

This study is, to our knowledge, the first to test the hypothesis that the effect of differences between invasive and native plant traits on ecosystem properties is modified predictably by the abiotic environment, as laid out in Fig. 1. Using meta-analysis to synthesize data from 51 studies our results show some support for this hypothesis. The effect of the difference in the $H_{\max }$ of invasive and native species on aboveground biomass was altered by climatic water deficit. Greater differences in $H_{\text {max }}$ led to increases in aboveground biomass, but greater water stress limited these increases. However, changes in soil carbon were solely influenced by the difference in the $H_{\max }$ of the invasive and native species. Along with Castro-Diez et al. (2014) our study is, to our knowledge, the only one showing evidence that the difference in invasive and native species characteristics is an important predictor of the impact of the invasive species. Our study also suggests that the difference in traits between the invasive and the dominant native species is a more informative predictor of changes in ecosystem function than the invasive species traits alone.

\section{Effects of trait differences and climate on carbon pools}

Our study indicates that as the climatic water deficit increases the effect of differences in invasive and native species $H_{\max }$ on aboveground biomass is reduced. Empirical data suggests that the size of plants can be limited by water stress (Moles et al. 2009, Stegen et al. 2009). As a result, increased water stress may reduce the size attainable by invasive plant species (Jakobs et al.

TABLE 1. Coefficient estimates of the most parsimonious models for post-invasion changes in aboveground biomass and soil carbon.

\begin{tabular}{lcccccc}
\hline \hline$Y$ variable & Parameter & Coefficient & SE & $\begin{array}{c}\text { Lower confidence } \\
\text { interval }\end{array}$ & $\begin{array}{c}\text { Upper confidence } \\
\text { interval }\end{array}$ & $P$ value \\
\hline $\begin{array}{l}\text { Aboveground } \\
\text { biomass }\end{array}$ & Intercept & 0.45 & 0.29 & -0.12 & 1.01 & 0.12 \\
& CWD & -0.16 & 0.3 & -0.43 & 0.75 & 0.59 \\
Soil carbon & $H_{\text {diff }}$ & 0.88 & 0.1 & 0.69 & -0.07 & 0.001 \\
& $H_{\text {diff }} \times$ CWD & 0.16 & 0.07 & -0.29 & 0.31 & 0.016 \\
& Intercept & 0.16 & 0.07 & 0 & 0.18 & 0.059 \\
\hline
\end{tabular}

Note: Estimates were obtained by bootstrapping the models with lowest $\mathrm{AIC}_{\mathrm{c}}$ to select sites that were truly independent with 1000 iterations. 


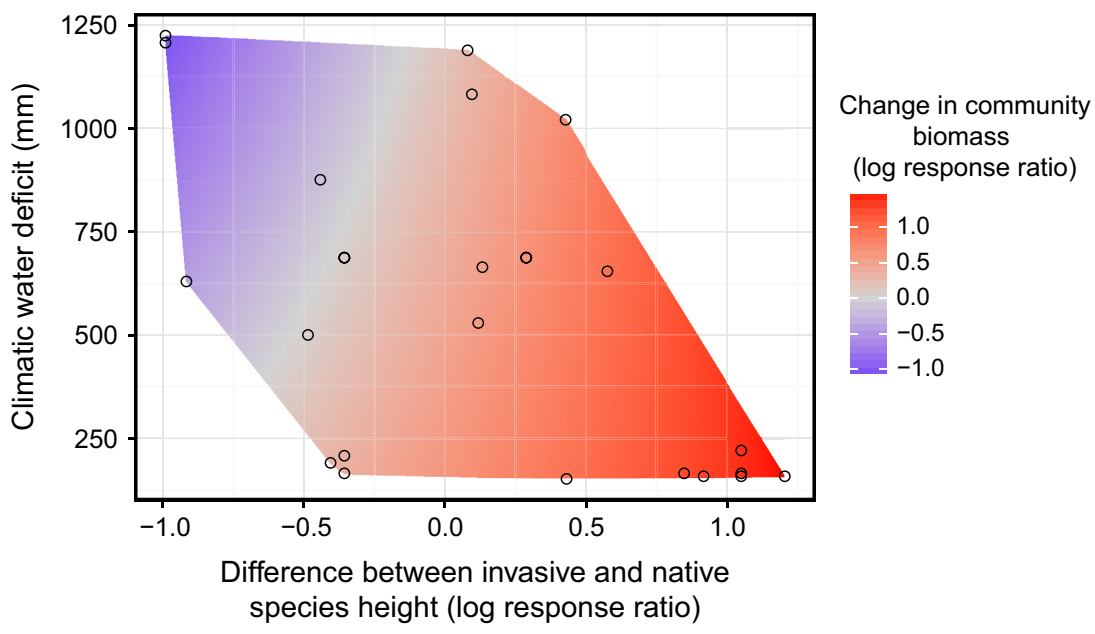

FIG. 2. Change in community biomass following invasion is governed by the difference in invasive and native species height and climatic water deficit $\left(R^{2}=0.30, n=27\right)$. Red color indicates gains in biomass and blue losses in biomass. [Color figure can be viewed at wileyonlinelibrary.com]

2004), limiting increases in aboveground carbon pools. We suggest that the interaction between $H_{\text {diff }}$ and climate observed in our study is a result of this alteration in attained plant size. It is also interesting to note that our model predictions suggested that post-invasion biomass increases even when invasive and native plants are of similar height. This may be for a number of reasons. Firstly, invasive plant species appear to grow larger outside of their native range (Thébaud and Simberloff 2001, Parker et al. 2013) possibly owing to a lack of natural enemies (Keane and Crawley 2002). Secondly, the traits of invasive species, other than plant height, may differ from those of native species, resulting in increases in biomass. Aside from plant height, root depth may be themost useful trait for predicting changes in aboveground biomass accumulation, with deeper rooting plants able to take advantage of water outside of the reach of other plants (Lavorel and Garnier 2002). However, little information is available on root depth in trait databases. The TRY database (Kattge et al. 2011; www.try-db.org) currently contains root depth estimates for only 54 plant species, as opposed to plant height estimates for 26,837 species. As a result inclusion of data on rooting depth in any synthesis is currently not possible.

In contrast to the trait-climate interaction that determined changes in aboveground biomass, soil carbon was only influenced by differences in native and invasive species height. This suggests that invasion by larger plants resulted in increases in soil carbon pools as has been observed following woody encroachment of grasslands (Eldridge et al. 2011). However, our model explained relatively little of the variation in post-invasion soil carbon changes, suggesting that there may be other important factors we did not account for in this study, including leaf traits (Díaz et al. 2015). The majority of soil carbon originates from dead roots rather than aboveground sources (Rasse et al. 2005),

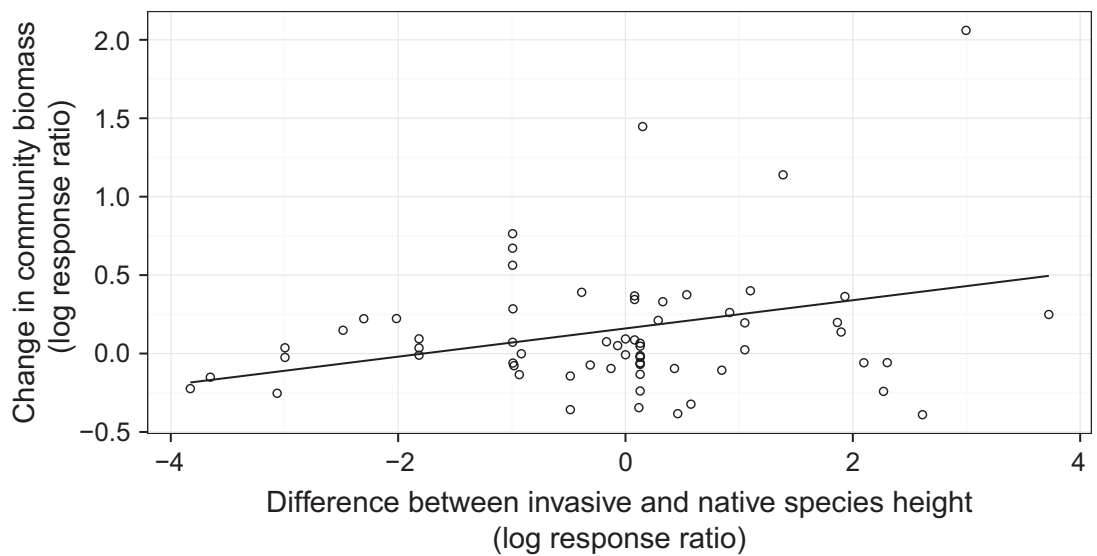

FIG. 3. Relationship between differences in invasive and native species height and changes in soil carbon following invasion. Points indicate pair-wise comparisons between invaded and uninvaded ecosystems, with the solid line representing predictions from the best supported meta-regression model $\left(R^{2}=0.09, n=62\right)$. 
(a)
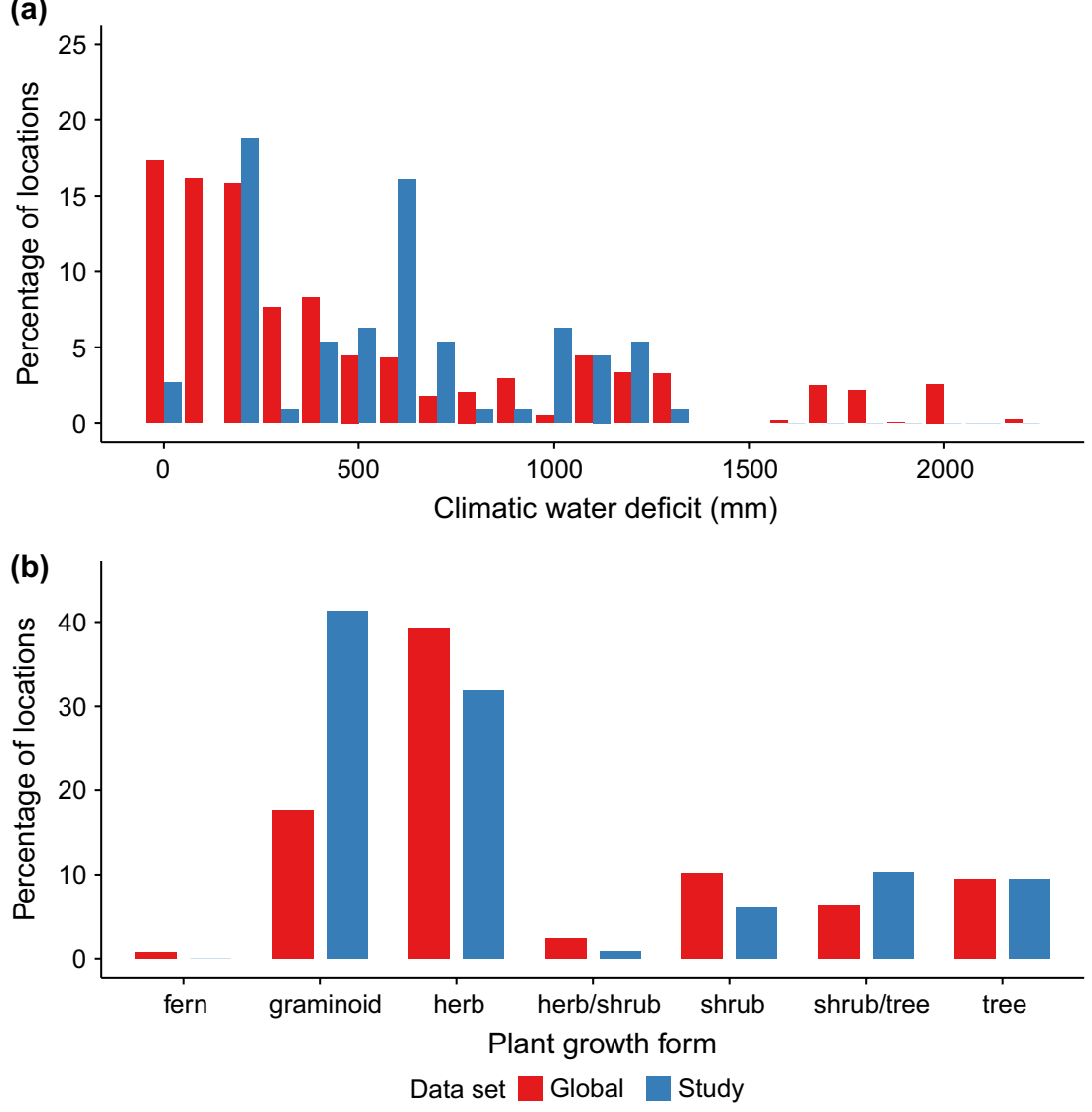

FIG. 4. Biases in (a) climatic water deficit and (b) invasive plant growth forms used in this study relative to data collated on locations invaded by all non-native invasive plant species from the CABI invasive species compendium. [Color figure can be viewed at wileyonlinelibrary.com]

but, given that aboveground and belowground biomass are highly correlated (Mokany et al. 2006) our analysis should have partly accounted for differences in plant rooting depth.

Generalizing about the effects of invasive species on soil carbon pools is challenging because it is determined by many interacting factors. These factors can be classified into three groups: factors that alter the amount and quality of plant litter, factors that control the flow of carbon from plant litter to soil organic matter, and factors that determine the stabilization of organic material in soils (Cotrufo et al. 2013). In this study, we investigated the influence of difference in invasive and native plant height and climate, which primarily determine the volume of plant litter. However, increases in the volume of leaf litter following non-native invasion do not always result in increases in soil carbon (Tamura and Tharayil 2014, Craig et al. 2015). The characteristics of aboveground litter, such as lignin to nitrogen ratios (Prescott 2010) and leaf mass per area (Cornwell et al. 2008), also strongly influence the rate at which the litter decays. In the case of roots, which are a major source of soil carbon, variations in the calcium content and carbon to nitrogen ratios strongly influence decay rates (Silver and Miya 2001). Even in ecosystems invaded by the same plant species differences in soil characteristics such as $\mathrm{pH}$, and clay content can strongly influence changes in soil carbon (Kramer et al. 2012) by altering the efficiency with which plant material is incorporated into microbial biomass (Cotrufo et al. 2013). Once incorporated into soil the long-term retention of organic material is determined by interactions with the soil matrix (Cotrufo et al. 2013). In our analysis, it was impossible to account for all of these factors, but we urge researchers to investigate this topic further given that the effects of invasive plants on soil carbon pools appear to be widespread.

Importantly in the case of both biomass and soil carbon the height of invasive species $\left(H_{\text {Inv }}\right)$ was a poorer predictor of change than $H_{\text {diff }}$. Thus, both this study and that of Castro-Diez et al. (2014) suggest that using information on both native and invasive traits may produce more informative predictions of post-invasion changes than solely using information about invasive species. While some previous syntheses of the impact of invasive plant species on ecosystems have solely used information on invasive species traits (e.g., Pyšek et al. 2012) we suggest that the using the difference between native and invasive species' traits may help researchers to generalize about the impacts of invasive plant species in the future. 
A key assumption of our paper is that invasive species displace or reduce the abundance of a single native species that is dominant in the uninvaded system and that the invasive species subsequently becomes dominant. This is unlikely to have been the case in all studies. However, the dominant species in a plant community is likely to indicate the maximum vegetation height and so be a good proxy for the state of the community prior to invasion. Furthermore, very few papers report percentage cover of species, hampering any analyses accounting for differences in abundance. Increased recording of abundance of invasive species in studies that aim to estimate their impacts would aid syntheses in the future and allow greater generalization about the per capita effects of invaders (Parker et al. 1999).

In addition to differences in abundance, our analysis did not allow us to consider the effects of the time since invasion occurred on carbon pools. This variable is rarely recorded (Strayer et al. 2006) but plays an important role in the effects of invasive plant species on ecosystem processes which may take decades to achieve a new postinvasion equilibrium. Encroachment of woody invasive species in open ecosystems tends to increase aboveground biomass (Eldridge et al. 2011), but as succession progresses and woody species increase in size and number, biomass will eventually plateau. Soil processes, in particular, may take a long time to be altered by plant invasions (Strayer et al. 2006). For example, displacement of woody species by shorter herbaceous species may not immediately lead to a reduction in soil carbon, since woody roots may persist in the soil (Johnson and Wilcock 2002, Strayer et al. 2006). We echo the views of Strayer et al. (2006) that more studies should investigate the temporal dynamics of the effects of invasive species to allow assessment of their long-term impacts.

\section{Do invasives have positive effects on carbon pools?}

The changes in carbon stocks predicted in our analysis of biomass range from decreases of $\sim 60 \%$ to increases of $\sim 170 \%$, while for soil carbon they range from decreases of $\sim 20 \%$ to increases of $\sim 65 \%$. Thus, it is clear that invasive plant species can have significant impacts on the carbon pools of the ecosystems they invade, often increasing carbon pools (Liao et al. 2008, Vilà et al. 2011) and thus enhancing the ecosystem service of climate regulation. This may result in management conflicts when biodiversity is negatively affected by invasion, as seen in New Zealand where restoration of a grassland invaded by pine species was halted because of potential carbon emissions (Dickie et al. 2011). However, our work also shows that relatively short invasive species can cause losses in carbon pools, particularly in arid ecosystems, suggesting that if their impact on biodiversity is equal to that of taller species their eradication should be prioritized. Increases in aboveground biomass following invasion also have the potential to alter water supply, with increased biomass often resulting in higher evapotranspiration and reduced stream flow (Jackson et al. 2005). Indeed, a number of programs to eradicate invasive plants do so specifically to increase water supply for local communities (Le Maitre et al. 2002, 2015). As a result, though increased carbon storage may be seen as a positive from the perspective of climate mitigation, assessing ecosystem service tradeoffs that occur as a result of invasions is vitally important.

\section{Potential biases}

Our exploration of biases suggested that our study overrepresented areas with low-intermediate CWD, but underrepresented areas that were highly water stressed. As a result of this undersampling, it is unclear whether our findings can be applied to highly water stressed ecosystems. Our study overrepresented invasive grass species but underrepresented herb species with tree and shrub species well represented. Underrepresentation of herbs may have resulted in relatively few studies where invasive species were shorter than native species; but given that we used data from studies which estimated the effect of invasive species of all growth forms, taxonomic biases are likely to have had little effect on our results. Assessing the biases of our study is difficult because the records of invasive species we based our analysis of bias on are themselves highly biased (Pautasso and McKinney 2007, Pyšek et al. 2008). As with many syntheses in ecology, our study shows a bias towards North America and Europe (Martin et al. 2012, Gonzalez et al. 2016), but it is also unclear whether in reality more invasive species occur in these regions than elsewhere.

\section{ConCLusions}

Our paper is amongst the first to show that the impacts of invasive species depend on differences between native and invasive species traits, rather than solely the trait values of the invasive species. This represents a significant advance compared to previous syntheses which have only used the trait values of invasive species to predict impact (Pyšek et al. 2012, but see Castro-Diez et al. 2014). Based on the findings of this study and that of Castro-Diez et al. (2014), we recommend that future research takes into consideration both invasive and native species traits when assessing the impacts of invasive plant species. We have extended this concept by showing that trait differences may be modified by abiotic conditions, specifically our finding that climatic water deficit altered the impact of differences in height on aboveground biomass changes. These findings suggest a framework by which the traits of invasives measured in their native ranges can be combined with information on native species' traits and abiotic conditions in the invaded systems to predict where impacts on ecosystem services are likely to be greatest. This framework may allow improved predictions of the impact of invasive species, and identification of ecosystems at particular risk. More direct understanding of 
the predictive power of trait differences will be achieved if researchers take heed of Hulme and Barrett (2013) and measure the traits of invasive species in their non-native and native ranges. This may allow researchers in the future to go beyond using species-level averages of traits and determine the likely trait values of species under a range of environmental conditions. The ability to do this would greatly further the utility of trait based approaches for predicting species' impact.

\section{ACKNOWLEDGMENTS}

PM was supported by a NERC PhD algorithm grant and along with JMB, by CEH Project NEC05264. Thanks to Tom August, Rory O'Connor, and Louise Colwill for statistical advice.

\section{Literature Cited}

Borenstein, M., L. V. Hedges, J. P. T. Higgins, and H. R. Rothstein. 2009. Effect sizes based on means. Pages 21-32 in M. Borenstein, L. V. Hedges, J. P. T. Higgins, and H. R. Rothstein, editors. Introduction to meta-analysis. John Wiley \& Sons, Ltd, Oxford, UK.

Castro-Diez, P., O. Godoy, A. Alonso, A. Gallardo, and A. Saldana. 2014. What explains variation in the impacts of exotic plant invasions on the nitrogen cycle? A meta-analysis. Ecology Letters 17:1-12.

Chave, J., et al. 2014. Improved allometric models to estimate the aboveground biomass of tropical trees. Global Change Biology 20:3177-3190.

Corbin, J. D., and C. M. D'Antonio. 2012. Gone but not forgotten? Invasive plants' legacies on community and ecosystem properties. Invasive Plant Science and Management 5:117-124.

Cornwell, W. K., et al. 2008. Plant species traits are the predominant control on litter decomposition rates within biomes worldwide. Ecology Letters 11:1065-1071.

Cotrufo, M. F., M. D. Wallenstein, C. M. Boot, K. Denef, and E. Paul. 2013. The Microbial Efficiency-Matrix Stabilization (MEMS) framework integrates plant litter decomposition with soil organic matter stabilization: Do labile plant inputs form stable soil organic matter? Global Change Biology 19:988-995.

Craig, M. E., S. M. Pearson, and J. M. Fraterrigo. 2015. Grass invasion effects on forest soil carbon depend on landscapelevel land-use patterns. Ecology 96:2265-2279.

Curran, M., S. Hellweg, and J. Beck. 2014. Is there any empirical support for biodiversity offset policy? Ecological Applications 24:617-632.

Davidson, A. M., M. Jennions, and A. B. Nicotra. 2011. Do invasive species show higher phenotypic plasticity than native species and if so, is it adaptive? A meta-analysis. Ecology Letters 14:419-431.

Díaz, S., et al. 2015. The global spectrum of plant form and function. Nature, 529:1-17.

Dickie, I. A., et al. 2011. Ecosystem service and biodiversity trade-offs in two woody successions. Journal of Applied Ecology 48:926-934.

Eldridge, D. J., M. A. Bowker, F. T. Maestre, E. Roger, J. F. Reynolds, and W. G. Whitford. 2011. Impacts of shrub encroachment on ecosystem structure and functioning: towards a global synthesis. Ecology Letters 14:709-722.

Fitter, A. H., and H. J. Peat. 1994. The Ecological Flora Database. Journal of Ecology 82:415.

Funk, J. L. 2008. Differences in plasticity between invasive and native plants from a low resource environment. Journal of Ecology 96:1162-1173.
Gonzalez, A., et al. 2016. Estimating local biodiversity change: a critique of papers claiming no net loss of local diversity. Ecology 97:1949-1960.

Hedges, L. V., J. Gurevitch, and P. S. Curtis. 1999. The metaanalysis of response ratios in experimental ecology. Ecology 80:1150-1156.

Hulme, P. E., and S. C. H. Barrett. 2013. Integrating trait- and niche-based approaches to assess contemporary evolution in alien plant species. Journal of Ecology 101:68-77.

Hulme, P. E., et al. 2015. Challenging the view that invasive non-native plants are not a significant threat to the floristic diversity of Great Britain. Proceedings of the National Academy of Sciences USA 112:E2988-E2989.

Jackson, R. B., E. G. Jobbágy, R. Avissar, S. B. Roy, D. J. Barrett, C. W. Cook, K. A. Farley, D. C. le Maitre, B. A. McCarl, and B. C. Murray. 2005. Trading water for carbon with biological carbon sequestration. Science 310:1944-1947.

Jakobs, G., E. Weber, and P. J. Edwards. 2004. Introduced plants of the invasive Solidago gigantea (Asteraceae) are larger and grow denser than conspecifics in the native range. Diversity and Distributions 10:11-19.

Johnson, A. C., and P. Wilcock. 2002. Association between cedar decline and hillslope stability in mountainous regions of southeast Alaska. Geomorphology 46:129-142.

Kattge, J., et al. 2011. TRY - a global database of plant traits. Global Change Biology 17:2905-2935.

Keane, R. M., and M. J. Crawley. 2002. Exotic plant invasions and the enemy release hypothesis. Trends in Ecology \& Evolution 17:164-170.

Kleyer, M., et al. 2008. The LEDA traitbase: a database of lifehistory traits of the Northwest European flora. Journal of Ecology 96:1266-1274.

Kramer, T. D., R. J. Warren, Y. Tang, and M. A. Bradford. 2012. Grass invasions across a regional gradient are associated with declines in belowground carbon pools. Ecosystems 15:1271-1282.

Lavorel, S., and E. Garnier. 2002. Predicting changes in community composition and ecosystem functioning from plant traits: revisiting the Holy Grail. Functional Ecology 16: $545-556$.

Le Maitre, D. C., M. B. Gush, and S. Dzikiti. 2015. Impacts of invading alien plant species on water flows at stand and catchment scales. AoB Plants 7:plu043.

Le Maitre, D. C., B. W. van Wilgen, C. M. Gelderblom, C. Bailey, R. A. Chapman, and J. A. Nel. 2002. Invasive alien trees and water resources in South Africa: case studies of the costs and benefits of management. Forest Ecology and Management 160:143-159.

Liao, C., R. Peng, Y. Luo, X. Zhou, X. Wu, C. Fang, J. Chen, and B. Li. 2008. Altered ecosystem carbon and nitrogen cycles by plant invasion: a meta-analysis. New Phytologist 177:706-714.

Martin, L. J., B. Blossey, and E. Ellis. 2012. Mapping where ecologists work: biases in the global distribution of terrestrial ecological observations. Frontiers in Ecology and the Environment 10:195-201.

Martin, P. A., A. C. Newton, E. Cantarello, and P. Evans. 2015a. Stand dieback and collapse in a temperate forest and its impact on forest structure and biodiversity. Forest Ecology and Management 358:130-138.

Martin, P. A., A. C. Newton, M. Pfeifer, M. Khoo, and J. M. Bullock. 2015b. Impacts of tropical selective logging on carbon storage and tree species richness: a meta-analysis. Forest Ecology and Management 356:224-233.

McGill, B. J., B. J. Enquist, E. Weiher, and M. Westoby. 2006. Rebuilding community ecology from functional traits. Trends in Ecology and Evolution 21:178-185. 
Mokany, K., R. Raison, and A. S. Prokushkin. 2006. Critical analysis of root: shoot ratios in terrestrial biomes. Global Change Biology 12:84-96.

Moles, A. T., D. I. Warton, L. Warman, N. G. Swenson, S. W. Laffan, A. E. Zanne, A. Pitman, F. A. Hemmings, and M. R. Leishman. 2009. Global patterns in plant height. Journal of Ecology 97:923-932.

Parker, I. M., et al. 1999. Impact: toward a framework for understanding the ecological effects of invaders. Biological Invasions 1:3-19.

Parker, J. D., et al. 2013. Do invasive species perform better in their new range. Ecology 94:1-8.

Pautasso, M., and M. L. McKinney. 2007. The botanist effect revisited: plant species richness, county area, and human population size in the United States. Conservation Biology 21:1333-1340.

Pejchar, L., and H. A. Mooney. 2009. Invasive species, ecosystem services and human well-being. Trends in Ecology \& Evolution 24:497-504

Prescott, C. E. 2010. Litter decomposition: What controls it and how can we alter it to sequester more carbon in forest soils? Biogeochemistry 101:133-149.

Pullin, A. S. S., and G. B. B. Stewart. 2006. Guidelines for systematic review in conservation and environmental management. Conservation Biology 20:1647-1656.

Pyšek, P., V. Jarošík, P. E. Hulme, J. Pergl, M. Hejda, U. Schaffner, and M. Vilà. 2012. A global assessment of invasive plant impacts on resident species, communities and ecosystems: the interaction of impact measures, invading species' traits and environment. Global Change Biology 18:1725-1737.

Pyšek, P., et al. 2008. Geographical and taxonomic biases in invasion ecology. Trends in Ecology \& Evolution 23:237-244.

R Development Core Team. 2011. R: a language and environment for statistical computing. R Foundation for Statistical Computing, Vienna, Austria. http://www.R-project.org/

Rasse, D. P., C. Rumpel, and M. F. Dignac. 2005. Is soil carbon mostly root carbon? Mechanisms for a specific stabilisation. Plant and Soil 269:341-356.

Ricciardi, A., M. F. Hoopes, M. P. Marchetti, and J. L. Lockwood. 2013. Progress toward understanding the ecological impacts of nonnative species. Ecological Monographs 83:263-282.

Schielzeth, H. 2010. Simple means to improve the interpretability of regression coefficients. Methods in Ecology and Evolution 1:103-113.

Silver, W. L., and R. K. Miya. 2001. Global patterns in root decomposition: comparisons of climate and litter quality effects. Oecologia 129:407-419.

Smith, M. J., M. C. Vanderwel, V. Lyutsarev, S. Emmott, and D. W. Purves. 2013. The climate dependence of the terrestrial carbon cycle; including parameter and structural uncertainties. Biogeosciences Discussions 9:13439-13496.

Sodhi, N. S., T. M. Lee, L. P. Koh, and B. W. Brook. 2009. A meta-analysis of the impact of anthropogenic forest disturbance on Southeast Asia's biotas. Biotropica 41:103-109.

Stegen, J. C., N. G. Swenson, B. J. Enquist, E. P. White, O. L. Phillips, P. M. Jørgensen, M. D. Weiser, A. Monteagudo Mendoza, and P. Núñez Vargas. 2011. Variation in aboveground forest biomass across broad climatic gradients. Global Ecology and Biogeography 20:744-754.

Stegen, J. C., N. G. Swenson, R. Valencia, B. J. Enquist, and J. Thompson. 2009. Above-ground forest biomass is not consistently related to wood density in tropical forests. Global Ecology and Biogeography 18:617-625.

Strayer, D. L., V. T. Eviner, J. M. Jeschke, and M. L. Pace. 2006. Understanding the long-term effects of species invasions. Trends in Ecology and Evolution 21:645-651.

Suding, K. N., S. Lavorel, F. S. Chapin, J. H. C. Cornelissen, S. Díaz, E. Garnier, D. Goldberg, D. U. Hooper, S. T. Jackson, and M.-L. Navas. 2008. Scaling environmental change through the community-level: a trait-based responseand-effect framework for plants. Global Change Biology 14:1125-1140.

Tamura, M., and N. Tharayil. 2014. Plant litter chemistry and microbial priming regulate the accrual, composition and stability of soil carbon in invaded ecosystems. New Phytologist 203:110-124

Thébaud, C., and D. Simberloff. 2001. Are plants really larger in their introduced ranges? American Naturalist 157: 231-236.

Tummers, B. 2006. DataThief III. http://datathief.org/

Van Mantgem, P. J., and N. L. Stephenson. 2007. Apparent climatically induced increase of tree mortality rates in a temperate forest. Ecology Letters 10:909-916.

Viechtbauer, W. 2010. Conducting meta-analyses in R with the metafor package. Journal of Statistical Software 36:1-48.

Vilà, M., J. L. Espinar, M. Hejda, P. E. Hulme, V. Jarošík, J. L. Maron, J. Pergl, U. Schaffner, Y. Sun, and P. Pyšek. 2011. Ecological impacts of invasive alien plants: a meta-analysis of their effects on species, communities and ecosystems. Ecology Letters 14:702-708.

Violle, C., M.-L. Navas, D. Vile, E. Kazakou, C. Fortunel, I. Hummel, and E. Garnier. 2007. Let the concept of trait be functional! Oikos 116:882-892.

Wickham, H. 2015. rvest: Easily Harvest (Scrape) Web Pages. R package version 0.3.1. https://CRAN.R-project.org/package =rvest

Wilman, H., J. Belmaker, J. Simpson, C. de la Rosa, M. M. Rivadeneira, and W. Jetz. 2014. EltonTraits 1.0: species-level foraging attributes of the world's birds and mammals. Ecology 95:2027-2027.

\section{SUPPORTING INFORMATION}

Additional supporting information may be found in the online version of this article at http://onlinelibrary.wiley.com/ doi/10.1002/ecy.1711/suppinfo 